Research article

\title{
Seed dormancy testing and germination frequency determination of Psoralea corylifolia L., an endangered medicinal plant
}

\section{Poonam Arya* and Ragini Gothalwal}

Department of Biotechnology, Barkatullah University, Bhopal-462026, Madhya Pradesh

*Corresponding Author: ms.poonam_arya@rediffmail.com

[Accepted: 13 February 2017]

\begin{abstract}
Seed dormancy is one of important factor which prevent the cultivation of medicinally important plant Psoralea corylifolia. Mechanical dormancy is present in the seed due to hard seed coat. $P$. corylifolia is a slow growing species due to low germination percentage (5-7\%). Long gestation period and delicate field handling discourages the commercial cultivation of the plant so different treatments were used to break dormancy in seeds. Out of five different methods used $98 \%$ concentrated $\mathrm{H}_{2} \mathrm{SO}_{4}$ for about one hour was found to be best method for seed dormancy breakage. Statistical analysis of data was performed by one way ANOVA using Sigma State Software version 4.
\end{abstract}

Keywords: Psoralea corylifolia - ANOVA - Dormancy - Gestation period - Dormancy.

[Cite as: Arya P \& Gothalwal R (2017) Seed dormancy testing and germination frequency determination of Psoralea corylifolia L., an endangered medicinal plant. Tropical Plant Research 4(1): 49-54]

\section{INTRODUCTION}

Psoralea corylifolia L. (Indian bread root) is an endangered medicinally important plant (Fig. 1) distributed in tropical and subtropical region of world belonging to Fabaceae family (Jain 1994). In India it is seen along the road sides and waste place of the tropical regions. Especially in the semi-arid region of Rajasthan and Eastern district of Punjab, Bihar and Karnataka (Agrawal et al. 2013). The Hindi name of the plant is Babchi and bakuchi (Oudhiya 2001). It is an erect herb of height 30-180 cm that grows in winter season high. Leaves are broadly elliptical in shape, Flower shows indense axillary long-peduneled heads pods small $3.5-4.5 \mathrm{~mm} \times$ 2.0-3.0 mm, seeds are compressed mucronate dark chocolate to almost black one, smooth, adhering to the pericarp (Uikey et al. 2010). The plant is harvested by drug industry when it sets in to flowering. P. corylifolia is propagated by seed germination.

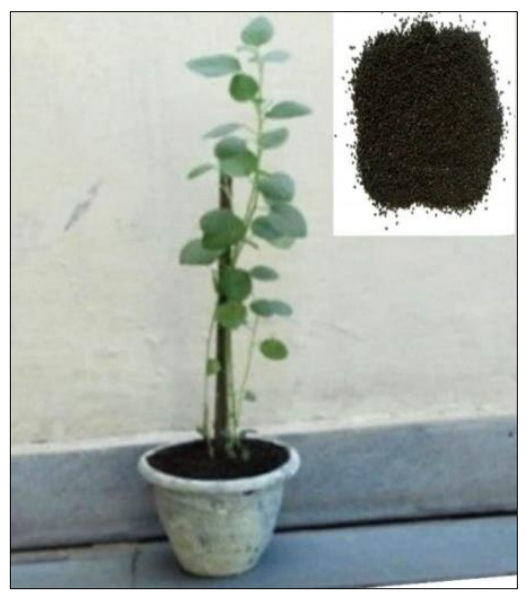

Scientific classification

Kingdom: Plantae

Division: Magnoliophyta

Class: Magnoliopsida

Order: Fabales

Family: Fabaceae

Genus: Psoralea

Species: Psoralea corylifolia L.

Figure 1. Plant of Psoralea corylifolia L. (Inset: Seeds)

\section{Active constituent of Psoralea corylifolia}

The major active constituents reported to be present in $P$. corylifolia seeds are corylifols a-c (prenylflavonoid) (Yin et al. 2004). Dried ripe fruit contains Psoralen, isopsoralen and neobavaislflavones 
(Rajput et al. 2008). Daidzein (4-7 dihydroxyisoflavonoid) and genistein (4, 5, 7 trihydroxy isoflavonoid) are present in natural plant as well as in vitro culture (Shinde et al. 2009).

\section{Medicinal Uses}

$P$. corylifolia has aromatic, antihelminthic, antibacterial and antifungal properties. It is used as a diuretic, diaphoretic, laxative and stimulant. The powdered seeds are applied externally to cure skin problems. It is valued as Chinese herbal medicine as a tonic remedy and is used to improve vitiligo. The roots are used for treating dental caries. Plant yields a useful medicinal oleoresin which treats kidney disorders, impotence and lumbago. The drug psoralen obtained from seed of P.corylifolia used for the treatment of vitiligo and leucoderma (Vaidya 2006).

\section{Dormancy}

Germination is prevented by dormancy mechanism during unsuitable ecological conditions, when the probability of seedling survival is low (Black et al. 2006). P. corylifolia has mechanical dormancy because its seed coats or other covering are too hard which prevent the embryo to expand during germination (Baskin \& Baskin 1999). In, environment condition the seed coats of physically dormant seeds become water permeable over time through repeated heating and cooling over many months to years in the soil. Chemical or pigment that is present around the covering of embryo may be leached out of the tissue by specific chemical method (Bewley \& Black 1994). P. corylifolia is a slow growing species due to low germination percentage (5-7\%). Long gestation period and delicate field handling discourages the commercial cultivation of the plant (Pandey et al. 2013).

The objective of this paper was to determine the effective method for breaking dormancy of Psoralea corylifolia with the purpose of increasing cultivation of medicinally important plant.

\section{MATERIAL AND METHODS}

Seeds were collected form MFP-PARC located at coordinate $23.2086^{\circ} \mathrm{N}, 77.4731^{\circ} \mathrm{E}$ Madhya Pradesh. State Minor Forest Produce Trading \& Development Co-operative Federation under the brand name "Vindhya Herbals" Located in Van Parisar, Barkheda Pathani, Near BHEL, Bhopal, Madhya Pradesh.

\section{Methodology for seed dormancy}

Five different treatments were performed to break seed dormancy.

a) Control

b) $98 \%$ Concentrated $\mathrm{H}_{2} \mathrm{SO}_{4}$ treatment for 1 hour and Hot water treatment $100^{\circ} \mathrm{C}$ for 20 min (Siva et al. 2014).

c) $1 \mathrm{~N} \mathrm{NaOH}$ treatment for 1 hour and Scarification by sand paper number 100 (Baes et al. 2002).

d) Cold water treatment Overnight incubation at $4^{\circ} \mathrm{C}$ (Fariman et al. 2011).

Seeds were washed with running tap water for $5 \mathrm{~min}$ to remove surface dust than washed with Tween 20 for about $1 \mathrm{~min}$ and then seeds were given different treatment then under aseptic conditions seeds were washed with double distilled water for about three times. $70 \%$ alcohol treatment was given to the seeds for about 1 min again washed with double distilled water three times than $0.1 \% \mathrm{HgCl}_{2}$ treatment was given for about 2 min again then they were used with double distilled water for about three times. With the help of sterile forceps seeds were transferred in petridishes having layers of blotting paper soaked with distilled water. Each petridishes has 50 seeds shoot length was recorded at regular intervals and final result was recorded after 28 days.

According to International Seed Testing Association: ISTA (2004), the germination test was performed in total 400 seeds in 4 groups each having 100 seeds. Present experiment was carried out in 8 petridishes each having 50 seeds $(8 \times 50=400)$.

\section{Methodology for seed germination}

Germination percent and percent of germination speed were calculated according to Krishnaswamy \& Seshu (1990).

1. Germination $(\%)=\frac{\text { Number of seeds germinated }}{\text { Total number of seeds }} \times 100$ 
2. Germination Speed $(\%)=\frac{\text { Number of seeds germinated at } 72 \mathrm{hrs}}{\text { Number of seeds germinated at } 168 \mathrm{hrs}} \times 100$

3. Germination energy $=$ Percentage of seed germinated at $72 \mathrm{hrs}$ (Bam et al. 2006).

4. Vigor Index $=$ Number of germinated seeds/day of first count $+\ldots \ldots+$ Number of germinated seeds/days at final count.

5. Fresh and dry weight of seed ling, seedling were dried in oven $70^{\circ} \mathrm{C}$ overnight.

\section{RESULT AND DISCUSSION}

Five different treatment performed for seed dormancy shows that $98 \%$ concentrated $\mathrm{H}_{2} \mathrm{SO}_{4}$ has maximum seedling length, germination frequency, germination energy, germination speed, germination vigor index, fresh weight (g), dry weight $(\mathrm{g})$ as compared to control.
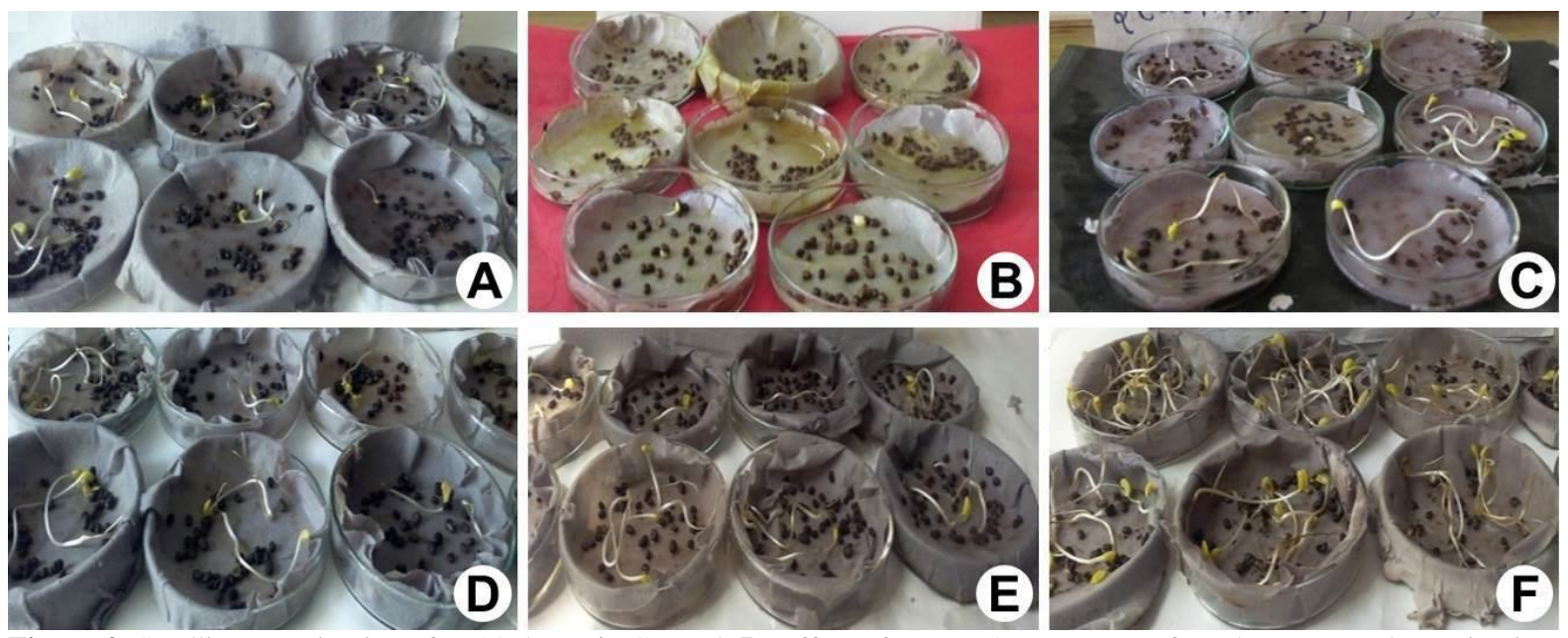

Figure 2. Seedling germination after 28 days: A, Control; B, Effect of $1 \mathrm{~N} \mathrm{NaOH}$ treatment for 1 hour on seed germination; C, Effect of Scarification by sand paper number $100 \mathrm{P}$ on seed germination; D, Effect of Hot water treatment $100^{\circ} \mathrm{C}$ for 20 min on seed germination; E, Effect of Cold water treatment overnight incubation at $4^{\circ} \mathrm{C}$ on seed germination; $\mathbf{F}$, Effect of 98\% Concentrated $\mathrm{H}_{2} \mathrm{SO}_{4}$ treatment for 1 hour on seed germination.
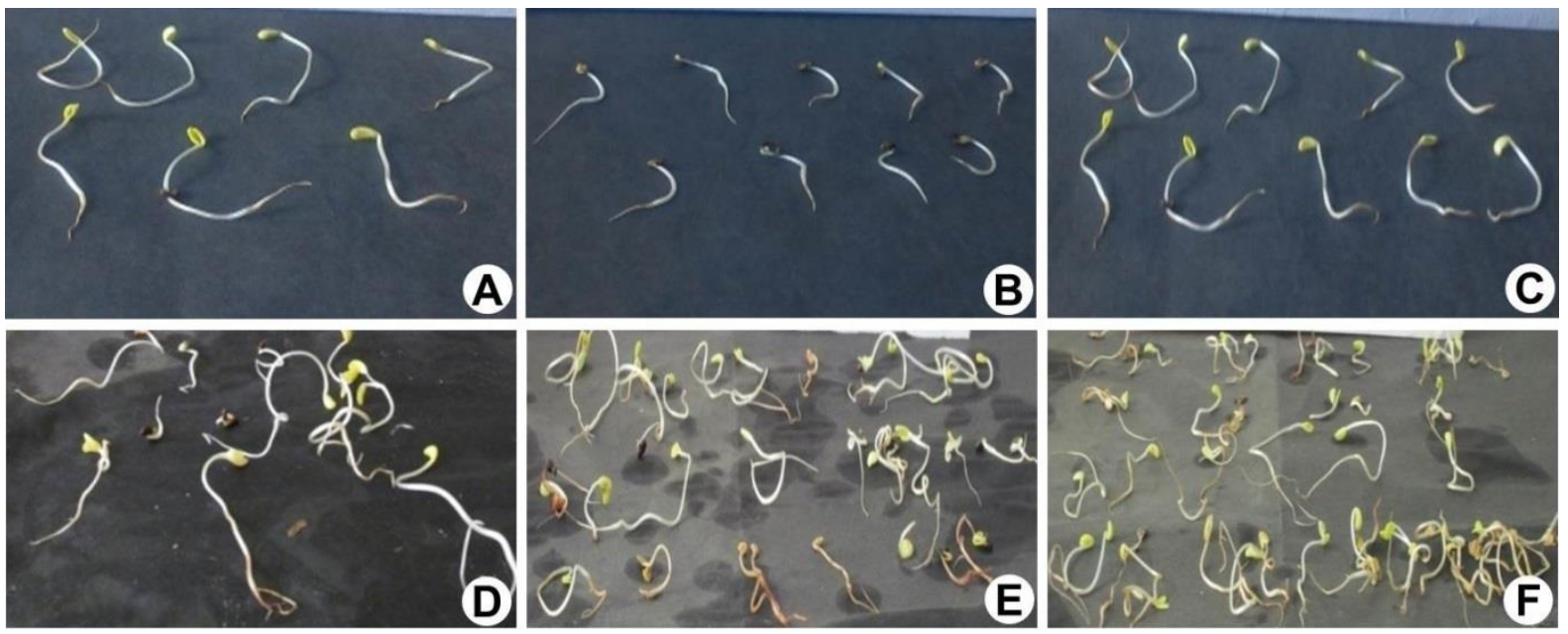

Figure 3. Shoot length determination after 28 days: A, Control; B, Effect of $1 \mathrm{~N} \mathrm{NaOH}$ treatment for 1 hour on seed germination; C, Effect of Scarification by sand paper number $100 \mathrm{P}$ on seed germination; D, Effect of Hot water treatment $100^{\circ} \mathrm{C}$ for $20 \mathrm{~min}$ on seed germination; E, Effect of Cold water treatment overnight incubation at $4^{\circ} \mathrm{C}$ on seed germination; F, Effect of $98 \%$ Concentrated $\mathrm{H}_{2} \mathrm{SO}_{4}$ treatment for 1 hour on seed germination.

Seed dormancy is a unique feature of family Fabaceae; in P. corylifolia mechanical dormancy is present. To overcome the dormancy and to increase the germination frequency five different treatments were used which breaks the dormancy. Sterile 400 seeds treated with different treatment for different time intervals were inoculated in petridishes having presoaked filter paper and they were incubated for 28 days at $28^{\circ} \mathrm{C}$ (Figs. $2 \mathrm{~A}-$ F). Subsequently the shoot length was calculated after 28 days (Figs. 3A-F). 


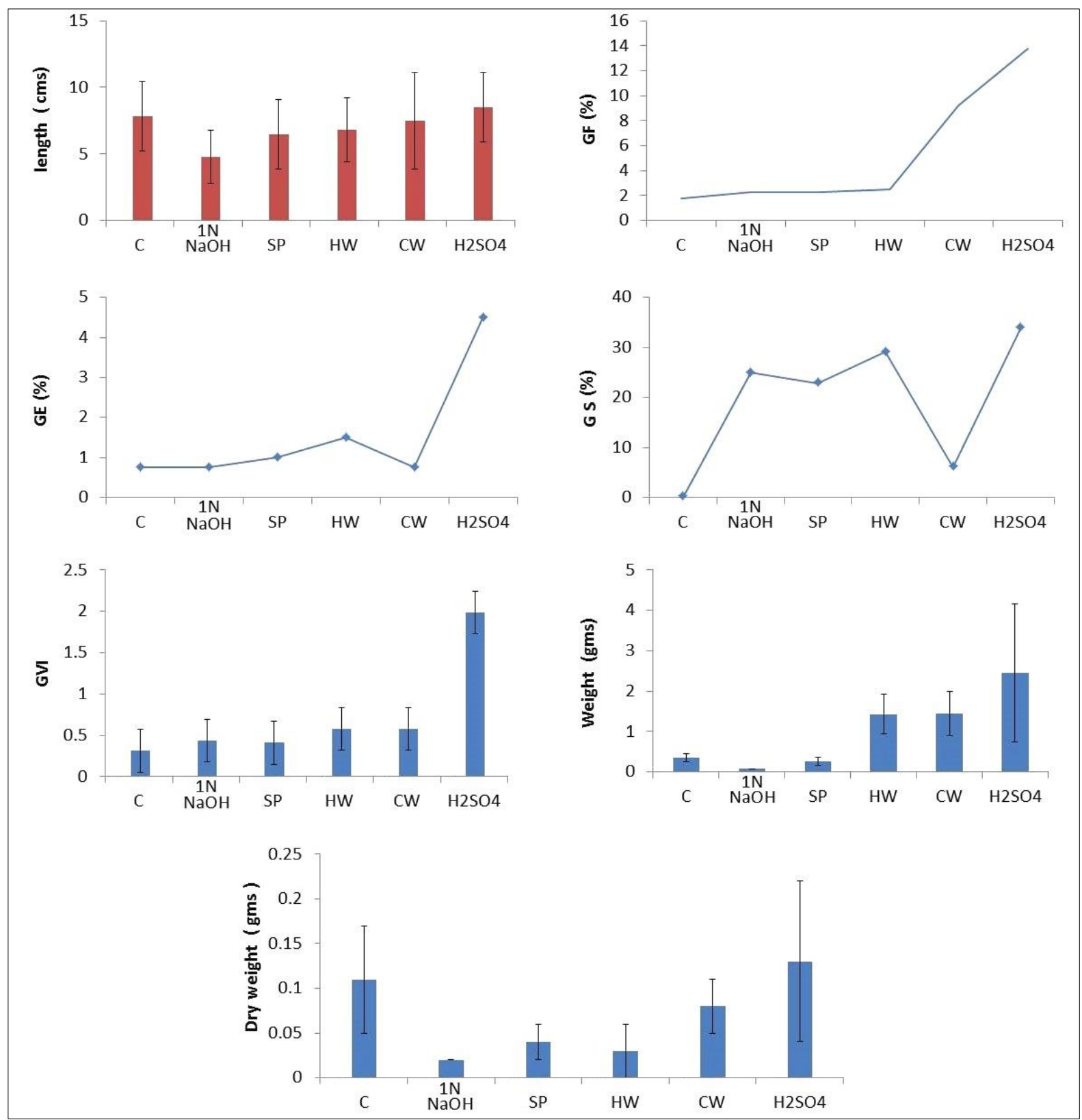

Figure 4. Effect of different treatment on dry weight of seedling after 28 days of germination.

Table 1. Effect of different treatment on germination parameter.

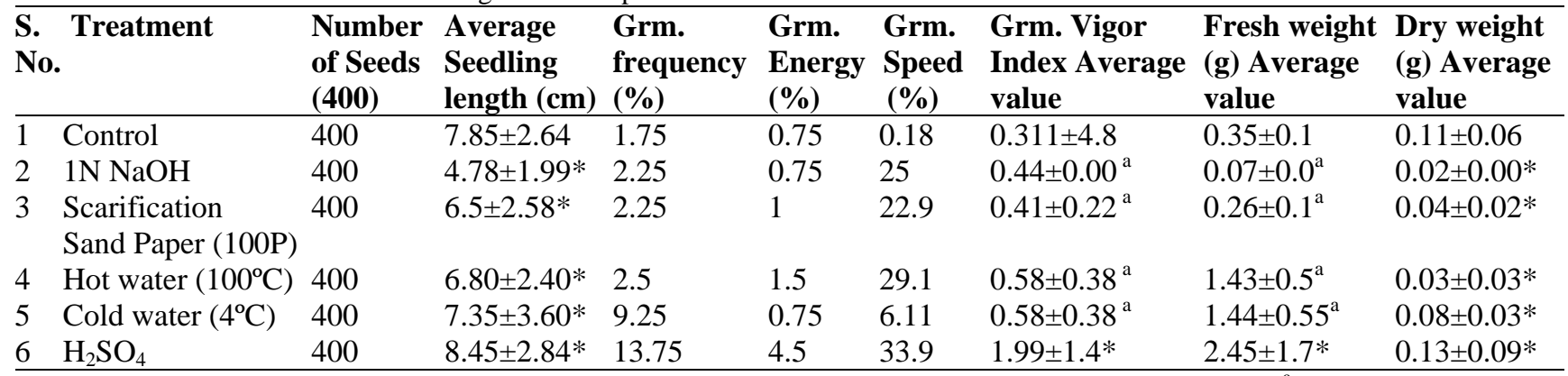

Note: Grm. = Germination; ${ }^{*}=$ Significance indicates significant value compared with control at $\left(\mathrm{P}=\langle 0.001) ;{ }^{a}=\right.$ indicates non significant value with control at $(\mathrm{P}=<0.001)$.

Different treatments have been used for seed germination parameters study and breaking seed dormancy in Psoralea corylifolia medicinal plant and they were compared with the control (Table 1). In the present study sulfuric acid treatment for one hour was effective in all seed germination parameter after 28 days (Fig. 4). Mechanical injury to the seed coat or chemical treatment has been used for breaking the seed dormancy of www.tropicalplantresearch.com 
certain cultivated medicinal plants Gloriosa superb, Echinacea purpurea, Belladonna (Gupta \& Shah 1971, Supari et al. 1993, Mittar et al. 1993, Kumar \& Sharma 2012).

The present study was first which compare different treatments for seed dormancy breakage in Psoralea corylifolia. The plant is listed as an 'endangered species' mainly due to the destruction of its natural habitats. Sulfuric acid and hot water pre-treatment have been reported that to improve the seed germination and seedlings growth of Cassia fistula (Soliman \& Abbas 2013). Primary exogenous dormancy due to physical factors present outside the embryo is present in most of the Fabaceae plants but in $P$. corylifolia mechanical dormancy is reported. Seed coats are too hard to allow the embryo to expand during germination. In Coronilla varia physical dormancy is present due to the low moisture level of seed, embryo gets quiescent. The outer macrosclereid and mucilaginous cell layer becomes impermeable to water. Or a hardened endocarp is three reasons that make seed coats impermeable to water. Such seed coats develop during the last stages of seed development. Whereas in $P$. corylifolia, acid breaks the seed layers and impermeable seed coat with helps in germination. Acid treatment was effective for breaking strong seed dormancy and impermeable seed coat which is the major cause low germination frequency in $P$. corylifolia. It is an effective, reliable and reproducible method to get high frequency seed germination in P. corylifolia, when compared to any other treatments, seeds Damaging and breaking possibilities are very low at this acid treatment. Thus, this method can be adopted as a good alternative than the other treatments for higher percentage of seed germination since; the aseptic seedlings were used as explants in large number of in vitro studies.

\section{ACKNOWLEDGEMENTS}

I would like to thanks UGC for RGNF Fellowship and Department of Biotechnology, Barkatullah University Bhopal for providing me lab facilities and chemicals for my research work.

\section{REFERENCES}

Agrawal V, Chetri SPK \& Parast BM (2013) In vitro evaluation of psoralen through nodal culture of Psoralea corylifolia exposed to elicitors. Acta Horticulturae 972: 9-20.

Baes O, DeViana ML \& Suhring S (2002) Germination in Prosopis ferox seeds, effect of mehincal, chemical and biological scarification. Journal of Arid Environment 50: 185-189.

Bam RK, Kumaga FK, Ofori K \& Asiedu EA (2006) Germination, Vigour and dehydrogenase activity of naturally aged rice (Oryza sativa L.) seeds soaked in potassium and phosphorus salts. Asian Journal of Plant Sciences 5: 948-955.

Baskin LiX \& Baskin JM (1999) Anatomy of two mechanisms of breaking physical dormancy by experimental treatments in seeds of two North American Rhus species (Anacardiaceae). American Journal of Botany 86: $1505-1511$.

Bewley JD \& Black M (1994) Seeds physiology of development and germination. The language of science. New York: Plenum Press. pp. 230.

Black M, Bewley JD \& Halme P (2006) The Encyclopedia of seeds. Wallingford, Oxfordshire: CAB International, pp. 1-16.

Fariman ZK, Azizi M \& Noori S (2011) Seed dormancy Breaking technique for Echinacea purpurea L. Journal of Biological Environmental Science 5(13): 7-10.

Gupta LK \& Shah SC (1971) Effect of chemicals on germination of Belladonna seeds. Progressive Horticulture 3 (2): 17-20.

Jain SK (1994) Ethanobotany and research in medicinal plant in India. In: Chadwick J \& Marsh J (eds) Ethanobotany and the search of new drugs. JohnWilly and Sons Inc., U.K., pp. 153-168.

Krishnaswamy V \& Seshu DV (1990) Germination after accelerate aging associated characters in rice varities. Seed Science and Technology 8: 147-150.

Kumar R \& Sharma S (2012) Effect of light and temperature on seed germination of important medicinal and aromatic plants in north western Himalayas. International Journal of Medicinal and Aromatic Plants 3(3): 468-475.

Mittar V, Srinivasan K \& Singh BM (1993) Overcoming hard seediness on Psoralea corylifolia. Seed Research 21 (1): 31-34.

Oudhiya P (2001) Traditional medicinal knowledge about herb Bemchi (Psoralea corylifolia) in chhatisgarh, India. Pharmacy 61(7): 312-332. 
Pandey P, Mehta R \& Upadhyay R (2013) In vitro propagation of an endangered medicinal plant Psoralea corylifolia Linn. Asian Journal of Pharmaceutical and Clinical Research 6(3): 115-118.

Rajput SJ, Vijaya Z \& Pallavi R (2008) Studies on extraction, isolation and estimation of Psoralea corylifolia. Pharmacological Magazine 4: 13.

Shinde AN, Malpathak N \& Fulzele DP (2009) Induced high frequency shoot regeneration and enhanced isoflavone production in Psoralea corylifolia. Records of Natural Products 3: 38-45.

Siva G, Shivkumar S, Premkumar G, Baskaran P, Senthikumar T \& Jayabalan N (2014) Enhanced seed germination of P. corylifolia L. by heat treatment. World Journal of Agricultural Research 2(4): 151-154.

Soliman ASH \& Abbas MS (2013) Effects of sulfuric acid and hot water pre - treatment on seed germination and seedlings growth of Cassia fistula. American-Eurasian Journal of Agricultural \& Environmental Sciences 13(1): 7-15.

Supari M R, Farooqui AA \& Prasad TG (1993) Influence of various pre-sowing treatments and growth regulators on seed germination in Gloriosa superba. Indian Journal of Forestry 16 (2): 123-126.

Uikey SK, Yadav AS, Sharma AK, Rai AK, Raghuwanshi DK \& Badkhane Y (2010) The Botany, Chemistry, Pharmacological and therapeutic application of Psoralea corylifoia Linn. A Review. International Journal of Phytomedicine 2(2): 100-107.

Vaidya AD (2006) Reverse Pharmacological correlates of Ayurvedic durg action. Indian Journal of Pharmacology 38: 311-315.

Yin S, Fan CQ, Wang Y, Dong L \& Yue JM (2004) Antibacterial prenylflavone derivative from Psoralea corylifolia and their structure - activity relationship study. Bioorganic \& Medicinal Chemistry 12(16): 4387-4392. 